\title{
A RELAÇÃO TEORIA-PRÁTICA NA FORMAÇÃO DO EDUCADOR E SEU SIGNIFICADO PARA A PRÁTICA PEDAGÓGICA DO PROFESSOR DE BIOLOGIA
}

\section{Theory-practice relationship in the qualification of educators and its meaning to the pedagogical practice of biology teacher}

\author{
Lia Cardoso Rocha Saraiva Teixeira* \\ Ana Mourão Oliveira * \\ *Licenciatura em Ciências Biológicas/Fac. Educação/ UFMG
}

\section{RESUMO}

Observações e experiências em nossa formação docente nos levaram a questionar a eficiência da aprendizagem por abordagens essencialmente práticas. Este estudo analisa como é trabalhada a relação teoria-prática na dinâmica do Curso de Licenciatura em Ciências Biológicas da Universidade Federal de Minas Gerais e as consequiências dessa abordagem na formação e prática pedagógica dos professores nele graduados. As ementas de algumas disciplinas foram cruzadas com os dados obtidos por meio de questionários submetidos a professores, alunos e ex-alunos desse curso. Com auxilio da literatura especializada conseguimos aprofundar a compreensão dos mecanismos de articulação e/ou dissociação entre teoria e prática, o que poderá contribuir para a construção de um currículo mais coerente com a realidade da sala de aula da educação básica.

Palavras-chave: relação teoria-prática, mediação didática, formação de professores de ciências.

\begin{abstract}
Our teaching observations and experiences have led us to challenge the efficacy of content transmission through essentially practical approaches. This study analyses how the theory-practice relation is dealt with in the dynamics of the UFMG Biological Sciences Teachers Course. The consequences of this approach in the qualification and in the pedagogical practice of the teachers who have graduated from this course are also analyzed. The programs of some subject-matters were crossed with data obtained
\end{abstract}


A relação teoria-prática na formação do educador

via questionnaires submitted to professors, students and alumni of this course. Supported by specialized literature, we succeeded in deepening our understanding of the theory-practice integration and dissociation mechanisms which may contribute to the elaboration of a curriculum more coherent with K-12 classroom reality.

Key words: theory-practice relation, didactical mediation, sciences teachers qualification.

\section{INTRODUÇÃO}

A idéia que estimulou a proposição desta pesquisa nasceu durante o estágio de regência vivenciado por nós, que gerou questionamentos a respeito da eficiência da aprendizagem a partir de abordagens essencialmente práticas. Esse contexto nos fez refletir sobre as disciplinas da Licenciatura do curso de Ciências Biológicas da UFMG, que segundo o nosso ponto de vista dão ênfase a atividades instrumentais, sem articulação com os conteúdos abordados nas disciplinas teóricas do curso.

$\mathrm{Na}$ elaboração do plano de aula para a regência sentimos muita dificuldade em montar uma aula clara e objetiva para alunos de ensino fundamental e médio. Não sabíamos como transformar o conteúdo científico estudado durante o nosso curso de Ciências Biológicas numa linguagem acessível a esses alunos. Percebemos que durante o nosso curso trabalhamos muitas atividades práticas voltadas para a educação básica, mas as abordagens teóricas ficaram bastante restritas ao âmbito científico.

A partir de nossas observações e experiências, acreditamos que os cursos de formação de professores deveriam fornecer uma fundamentação teórica associada a uma instrumentalização técnica, para uma ação mais coerente com a realidade da sala de aula. Encontramos eco a essa postura na literatura da área de Educação.

De acordo com FIORENTINI et al. (1998), as pesquisas sobre ensino e formação de professores priorizam o estudo de aspectos políticos e pedagógicos amplos, sendo os saberes escolares e os saberes docentes muito pouco valorizados e raramente problematizados ou investigados, tanto pela pesquisa acadêmica educacional como pelos programas de formação dos professores. Essa situação nos incentivou a buscar uma melhor compreensão de como a relação teoria-prática é estruturada no âmbito de um contexto pedagógico e a importância da unicidade desses dois pólos na prática pedagógica. 


\section{REFERENCIAL TEÓRICO}

$\mathrm{Na}$ relação teoria-prática se manifestam os problemas e contradições da sociedade em que vivemos que, como sociedade capitalista, privilegia a separação trabalho intelectual - trabalho manual e, conseqüentemente, a separação entre teoria e prática (CANDAU \& LELIS, 1999).

Ambos os termos derivam do grego, possuindo "teoria" o sentido de observar, contemplar, refletir, enquanto a palavra "prática", provinda de "práxis", relaciona-se ao agir, ao fato de agir e, principalmente, à interação inter-humana consciente (CANDAU \& LELIS, 1999).

Ainda segundo CANDAU \& LELIS (1999), a relação entre teoria e prática pode ser fundamentada em dois esquemas: a visão dicotômica e a visão de unidade.

A primeira está centrada na separação entre teoria e prática, com ênfase na total autonomia de uma em relação a outra. Dentro desta existe uma visão mais extremista, que as autoras denominam dissociativa, na qual a teoria e a prática são componentes isolados e mesmo opostos. Caberia assim aos teóricos pensar, elaborar, refletir, planejar, e aos práticos, executar, agir e fazer, tendo, cada um desses pólos, sua lógica própria. Já em uma visão associativa, estes pólos não são opostos. A prática deve ser uma aplicação da teoria e só adquirirá relevância na medida em que for fiel aos parâmetros desta, uma vez que a inovação vem sempre do pólo teórico.

$\mathrm{Na}$ visão de unidade, teoria e prática são dois componentes indissolúveis da "práxis" definida como atividade teórico-prática, ou seja, tem um lado ideal, teórico e um lado material, propriamente prático, com a particularidade de que só artificialmente, por um processo de abstração, podemos separar um do outro. Essa relação não é direta nem imediata, fazendo-se através de um processo complexo, no qual algumas vezes se passa da prática à teoria e outras desta à prática (VASQUEZ, 1977).

A separação, e mesmo oposição, entre teoria e prática é freqüentemente denunciada pelos educadores, ao mesmo tempo em que é explicitado o desejo de buscar novas formas de relacionamento entre estas duas dimensões da realidade. A visão de unidade expressa a síntese superadora da dicotomia entre teoria e prática, sendo condição fundamental para a busca de alternativas na formação do educador. Nesta alternativa, SAVIANI (1996) afirma que a teoria exprime interesses, objetivos e finalidades, se posicionando a respeito de qual rumo a educação deve tomar. Neste 
sentido, a teoria não é apenas retratadora ou constatadora do existente, é também orientadora de uma ação que permita mudar a realidade. Quanto à prática educacional, ela é sempre o ponto de partida e o ponto de chegada.

Desta forma, todos os componentes curriculares deveriam trabalhar a unidade teoria-prática sob diferentes configurações, para que não se perca a visão de totalidade da prática pedagógica e da formação como forma de eliminar distorções decorrentes da priorização de um dos dois pólos.

Entretanto, o que se observa na maioria dos cursos de preparação de docentes é que se prioriza a visão dissociativa (SANTOS, 1992). Segundo SCHON, (1982) o processo de formação de profissionais, inclusive o de professores, sofre grande influência do "modelo da racionalidade técnica", no qual a atividade profissional é sobretudo instrumental, dirigida para a solução de problemas, mediante a aplicação rigorosa de teorias e técnicas científicas fornecidas pelos pesquisadores. Esse modelo está presente nas relações entre pesquisa e prática e também nos currículos da educação profissional.

Já CANDAU \& LELIS (1999) afirmam que por um lado, está a tendência a enfatizar a formação teórica, estimulando o contato com os autores considerados clássicos sem se preocupar em modificar ou fornecer instrumentos para a intervenção na prática educacional. Em contrapartida, o foco pode estar na formação prática, admitindo-se que esta tem sua lógica própria, que independe da teoria. Neste caso, a prática é esvaziada da teoria, daí a ênfase nas disciplinas instrumentais, sem a preocupação com sua articulação com as disciplinas consideradas teóricas.

Essas tendências podem ser explicadas pela dificuldade em transformar o saber de referência em saber escolar. Essa reestruturação de saberes é chamada por CHEVALLARD (1985) de transposição didática. Já LOPES (1997) defende que o termo transposição didática não representa bem esse processo, uma vez que tende a ser associado à idéia de reprodução, movimento de transportar de um lugar a outro, sem alterações. Mais coerentemente deve-se referir a um processo de mediação didática, utilizando o termo mediação como processo de constituição de uma realidade através de mediações contraditórias, de relações complexas, não imediatas, com profundo sentido de dialogia.

No que diz respeito especificamente ao ensino das ciências, DEVELAY (1995a, 1995b) defende que as disciplinas e o conhecimento escolares são diferentes das disciplinas e do conhecimento científicos. O conhecimento escolar não tem apenas 
o conhecimento científico como saber de referência pois valores sociais são também incorporados.

Nesse contexto, permanece o desafio de pensar nas relações que o professor estabelece com os saberes, considerando-se que na ação prática, saberes de diferentes ordens são por ele mobilizados. Trabalhando as diferenças entre o cientista e o professor do ponto de vista da relação com o saber, SAVIANI (1985) afirma que enquanto o cientista está interessado em fazer avançar a sua área de conhecimento, em fazer progredir a ciência, o professor está mais interessado em fazer progredir o aluno. Este vê o conhecimento como um meio para o crescimento do aluno, cabendo a ele a organização dos processos e de métodos, de modo a garantir a produção de conhecimentos pelo aluno. Já para o cientista o conhecimento é um fim, trata-se de descobrir novos conhecimentos na sua área de atuação.

No interior do debate sobre a formação de professores, vão sendo aprofundados os problemas crônicos enfrentados pelas instituições formadoras: falta de articulação entre teoria e prática educacional, entre formação geral e formação pedagógica, entre conteúdos e métodos (LELIS, 2001). Pensando alternativas para o curso de licenciatura, CANDAU (1997) defende o primado do conteúdo específico sobre o conteúdo pedagógico. A formação básica de todo e qualquer professor se dá pelo domínio do conteúdo específico, a partir do qual é possível construir a competência pedagógica. Enquanto as unidades específicas não assumirem como responsabilidade própria a participação na formação de professores, as unidades de educação terão que arcar com essa deficiência. O que CANDAU (1997) propõe é uma nova concepção e uma reestruturação das relações de poder presentes na licenciatura, assumindo a necessidade de haver uma colaboração mútua entre as unidades específicas e de educação. Essa tomada de posição revela a importância de se investir no saber disciplinar, sem o qual não se efetiva a atividade de construção do conhecimento.

O objetivo deste estudo é analisar como é trabalhada a relação teoria-prática na dinâmica do Curso de Licenciatura em Ciências Biológicas da Universidade Federal de Minas Gerais e as conseqüências dessa abordagem na formação e na prática pedagógica dos professores graduados neste curso.

\section{DESENHO METODOLÓGICO}


A relação teoria-prática na formação do educador

Para a coleta de dados foram criados dois questionários. $\mathrm{O}$ primeiro consiste em 24 afirmativas ante as quais se pede aos sujeitos que externem suas opiniões, escolhendo um dentre cinco pontos de uma escala da seguinte forma: 1- concordo fortemente; 2- concordo; 3 - indeciso; 4 discordo; 5- discordo fortemente (ANEXO 1). O segundo questionário tem formato descritivo, apresentando quatro perguntas (ANEXO 2).

O primeiro questionário foi submetido a alunos e ex-alunos do curso de licenciatura em Ciências Biológicas/UFMG divididos em três grupos distintos: 16 alunos da disciplina Prática de Ensino em Ciências Biológicas; 8 ex-alunos do curso de Licenciatura em Ciências Biológicas que não estão lecionando; 11 professores de educação básica que são ex-alunos dessa Licenciatura. O questionário descritivo foi submetido a 8 professores da UFMG que lecionam disciplinas resse mesmo curso. As disciplinas escolhidas foram aquelas chamadas por PEREIRA (2000) de "integradoras". Segundo o autor, estas são responsáveis pela articulação entre as disciplinas de conteúdo específico e as pedagógicas, e na vinculação permanente das licenciaturas com o ensino médio e fundamental. Dessa forma, de acordo com o currículo do curso foram selecionadas as seguintes disciplinas: Didática de Licenciatura, Instrumentação/Laboratório do Ensino de Zoologia, Instrumentação/Laboratório do Ensino de Botânica, Instrumentação/Laboratório do Ensino de Ecologia, Laboratório de Ensino de Genética, Laboratório de Ensino de Microbiologia, Laboratório de Ensino de Fisiologia e Prática de Ensino de Ciências Biológicas.

Para a elaboração dos questionários utilizamos como base algumas questões propostas por CANDAU \& LELIS (1999) que ajudam a entender os mecanismos de articulação e/ou dissociação entre a teoria e a prática, para assim compreender melhor as práticas educativas relacionadas à formação do educador.

Os tópicos que nos orientaram para a elaboração dos questionários foram:

o Como é trabalhada a relação teoria-prática na dinâmica do Curso? Existe dissociação entre estes dois pólos? Como se traduz? Há predomínio de um sobre o outro? Como se revela?

o A fundamentação teórica está voltada para a prática a ser exercida pelo educador? Como se manifestam estas concepções na dinâmica do Curso?

o Há um predomínio do praticismo, isto é, da prática esvaziada da teoria? 
A relação teoria-prática na formação do educador

o Como está estruturado o currículo? Existe uma clara divisão entre disciplinas "teóricas" e "instrumentais"? Em que se manifesta? Como são encaradas as disciplinas consideradas "instrumentais"? Como aplicação dos conhecimentos teóricos? Como algo totalmente independente?

Depois de muitas correções e análise criteriosa de cada questão, chegamos às versões finais apresentadas nos ANEXOS 2 e 3.

As ementas das disciplinas utilizadas como referência (QUADRO 1) foram consultadas para nos ajudar a compreender melhor a estrutura do curso em questão e são apresentadas no QUADRO 2. As informações contidas nestas ementas foram analisadas conjuntamente com os dados obtidos através dos questionários.

QUADRO 1 - Disciplinas específicas da Licenciatura em Ciências Biológicas na Faculdade de Educação e no Instituto de Ciências Biológicas.

\begin{tabular}{|l|l|}
\hline \multirow{4}{*}{ Faculdade de Educação } & Sociologia da Educação \\
\cline { 2 - 3 } & Psicologia da Educação \\
\cline { 2 - 3 } & Política Educacional \\
\cline { 2 - 3 } Instituto de Ciências Biológicas & Didática de Licenciatura* \\
\cline { 2 - 3 } & Prática de Ensino* \\
\cline { 2 - 2 } & Estágio Monografia \\
\hline & Instrumentação/Laboratório** de Ensino de Ecologia* \\
\cline { 2 - 3 } & Instrumentação/Laboratório de Ensino de Botânica* \\
\cline { 2 - 3 } & Instrumentação/Laboratório de Ensino de Zoologia* \\
\cline { 2 - 3 } & Laboratório de Ensino de Microbiologia* \\
\cline { 2 - 3 } & Laboratório de Ensino de Genética* \\
\cline { 2 - 3 } & Laboratório de Ensino de Fisiologia* \\
\hline
\end{tabular}

* Disciplinas consideradas para análise.

** As Instrumentações são correspondentes aos Laboratórios de Ensino.

QUADRO 2 - Ementas das disciplinas da Licenciatura em Ciências Biológicas tomadas como referência neste trabalho. ${ }^{1}$

\begin{tabular}{|l|l|}
\hline \multicolumn{2}{|c|}{ Didática de Licenciatura } \\
\hline Ementa & $\begin{array}{l}\text { Papel da Didática na transformação da prática pedagógica. Componentes e } \\
\text { processos de ensino: objetivo, conteúdo, métodos, procedimentos e avaliação. } \\
\text { Relação professor-aluno, planejamentos como processo de organização do ensino. } \\
\text { Propostas alternativas de didática. }\end{array}$ \\
\hline Objetivos & $\begin{array}{l}\text { Refletir sobre as diferentes concepç̃̃es do processo de ensino aprendizagem que } \\
\text { têm norteado o trabalho dos educadores no Brasil; } \\
\text { Discutir os pressupostos teórico-metodológicos que fundamentam as diferentes } \\
\text { propostas de ensino aprendizagem; } \\
\text { Analisar os elementos do processo de ensino aprendizagem, tendo em vista a } \\
\text { elaboração de uma proposta alternativa de ensino. }\end{array}$ \\
\hline Conteúdos & $\begin{array}{l}\text { Didática e formação de professores para a educação básica } \\
\text { Didática e o processo de ensino aprendizagem: concepções }\end{array}$ \\
\hline
\end{tabular}




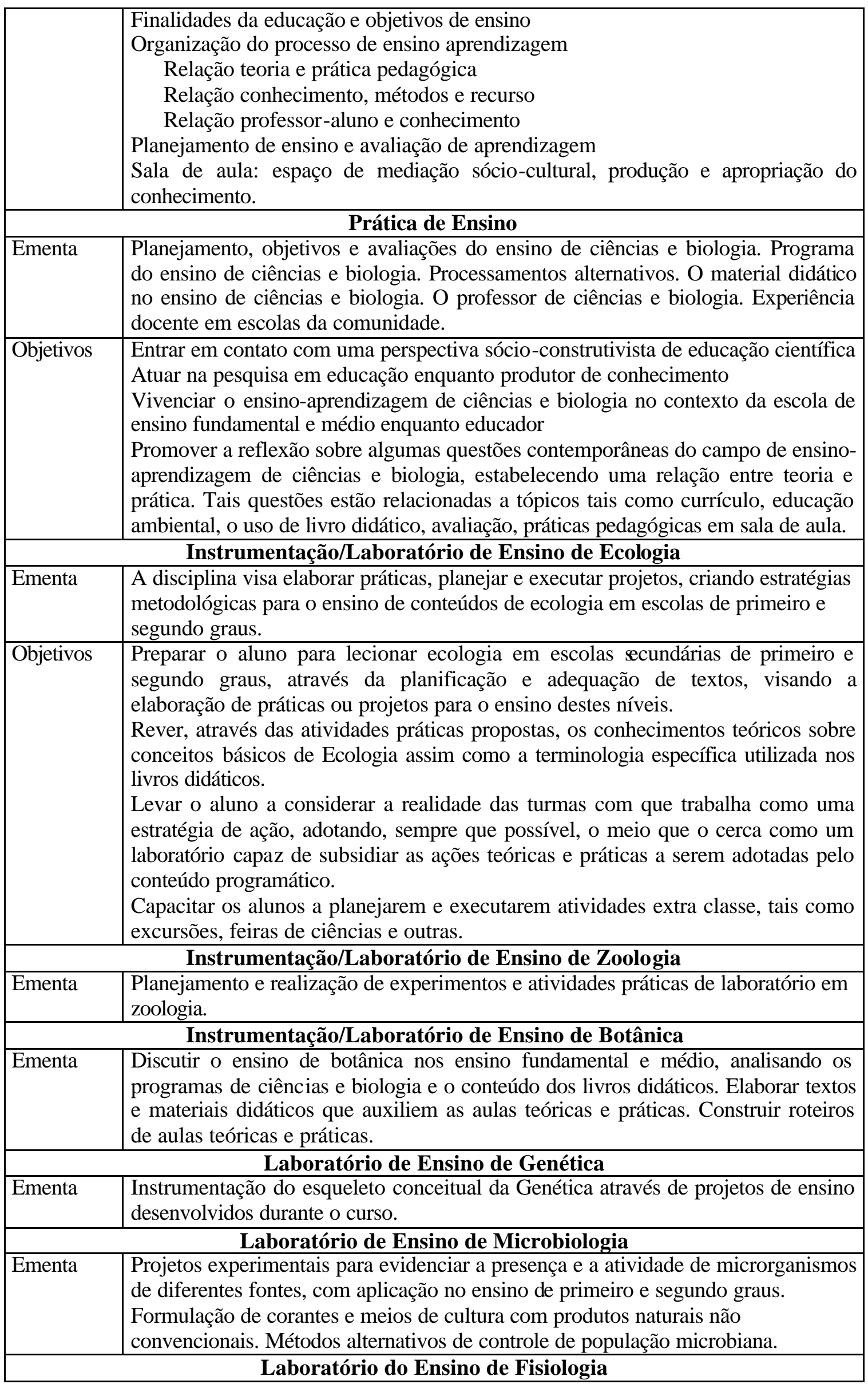


A relação teoria-prática na formação do educador

\begin{tabular}{|l|l|}
\hline Ementa & Fenômenos fisiológicos - estudo prático. \\
\hline
\end{tabular}

${ }^{1}$ Os dados acima foram retirados dos programas das respectivas disciplinas e em alguns deles os objetivos e os conteúdos não estavam especificados.

\section{Estratégia de análise dos dados}

Para uma melhor visualização dos resultados dos questionários submetidos aos alunos e ex-alunos do curso de licenciatura em Ciências Biológicas/UFMG foi feita a porcentagem para cada escala de respostas. Para a análise desses questionários, primeiramente foram computados os dados de todos os grupos conjuntamente para que pudéssemos obter uma visão geral da opinião dos entrevistados. Depois analisamos cada grupo separadamente comparando as diferenças existentes entre eles. Optamos por utilizar uma escala com cinco pontos a fim de minimizar o número de indecisões, uma vez que os entrevistados não precisam expressar sua opinião de forma absoluta. No entanto, as escalas 1, 2 (concordo fortemente; concordo) e 4, 5 (discordo e discordo fortemente) foram somadas para a discussão dos resultados, uma vez que exprimem uma mesma opinião, variando apenas o grau de concordância ou discordância. As questões foram analisadas relacionando-se umas com as outras, e em alguns casos uma mesma questão foi considerada mais de uma vez na discussão, já que os tópicos abordados estão estreitamente relacionados e por muitas vezes se entrecruzam.

Para a análise dos questionários descritivos, as respostas foram analisadas, cruzadas com as ementas e agrupadas de acordo com a convergência de opiniões referente aos temas: dicotomia/unificação na abordagem teórico-prática nas disciplinas, mediação didática e papel das unidades específicas e de educação na formação dos professores.

\section{RESULTADOS}

Em anexo são apresentadas as tabelas com as porcentagens das respostas totais e para cada grupo de entrevistados pelo questionário com 24 afirmativas (ANEXO 3).

Os questionários aplicados aos professores do curso de Licenciatura, por serem em um formato descritivo e buscarem dados qualitativos, não apresentam seus resultados aqui sistematizados, estando estes incluídos na análise e discussão. 


\section{ANÁLISE E DISCUSSÃO}

\section{- Questionário submetido aos alunos e ex-alunos do curso de licenciatura em Ciências Biológicas/UFMG}

Os dados mostram que $97 \%$ dos entrevistados sentem-se incomodados com o atual currículo da licenciatura e dão importância à formação do professor para a realização de uma boa prática pedagógica, não sendo esta determinada pelo dom ou pelo domínio do conteúdo, como foi constatado nas afirmativas 22 e 23. Essa formação deve incluir tanto o conteúdo científico quanto a abordagem prática, havendo sempre um diálogo entre esses dois pólos (afirmativas 13, 19 e 20).

Apesar de $71,3 \%$ dos entrevistados concordarem com o predomínio de prática nas disciplinas instrumentais da licenciatura (afirmativa 2), eles ainda assim se sentem mais preparados para ministrar aulas teóricas do que práticas (afirmativas 1 e 4). Mais da metade (57\%) dos que acreditam não ser papel das disciplinas instrumentais tratar da abordagem teórica (afirmativa 9) sente dificuldade em extrapolar o conteúdo teórico para uma atividade prática (afirmativa 16). Isso mostra que é dada uma maior importância à prática, gerando uma demanda por esta, mesmo que seja esvaziada da teoria.

Pela análise das afirmativas 3, 11, 17 e 21, percebemos que pelo menos $68 \%$ dos entrevistados estão cientes da importância da mediação didática para a realização de uma boa prática pedagógica. Uma vez que linguagem científica e linguagem escolar não possuem o mesmo significado, um bom professor deve reconstruir o saber científico para ser tilizado no contexto escolar (MORTIMER, 1998). MELLO (2000) afirma que cada conteúdo que é aprendido pelo futuro professor em seu curso de formação profissional precisa estar relacionado com o ensino desse mesmo conteúdo na educação básica. Isso implica um tipo de organização curricular que permita a mediação didática do conteúdo aprendido pelo futuro professor e a contextualização na realidade da educação básica, em todas as disciplinas do curso de formação.

Pela afirmativa 7 foi constatado que entre os entrevistados, $65,7 \%$ não sentem dificuldade de fundamentar uma atividade prática em um conteúdo teórico. Além disso, a grande maioria dos entrevistados $(74,2 \%)$ acredita que as atividades práticas das disciplinas instrumentais são relacionadas aos conteúdos teóricos correspondentes 
A relação teoria-prática na formação do educador

(afirmativa 14). No entanto, quando se trata de extrapolar a teoria, incluindo atividades práticas (afirmativa 16), o que pode ser entendido como uma proposta mais unificada desses dois pólos, apenas 34,2\% dos entrevistados se sentem seguros. Além disso, pela afirmativa 12 , podemos perceber que $59,9 \%$ das pessoas não se sentem preparadas pelo curso para fazer a mediação didática necessária para relacionar as atividades práticas com o conteúdo teórico correspondente. Portanto, considerando a divergência entre essas respostas, onde a maioria dos entrevistados considera-se preparada para fundamentar a prática na teoria (afirmativas 7 e 14) e, ao mesmo tempo, poucos se sentem seguros para realizar uma abordagem mais unificada e fazer a mediação didática (afirmativas 12 e 16), acreditamos que, em muitos casos, o conteúdo teórico referido nas questões 7 e 14 foi igualado ao saber científico, sem que este tenha passado por um processo de mediação. Dentro deste quadro, MELLO (2000) destaca a importância do professor ser capacitado para relacionar a teoria à prática:

Ora, se no futuro será necessário que o professor desenvolva em seus alunos a capacidade de relacionar a teoria à prática, é indispensável que, em sua formação, os conhecimentos especializados que o professor está constituindo sejam contextualizados para promover uma permanente construção de significados desses conhecimentos com referência à sua aplicação, sua pertinência em situações reais, sua relevância para a vida pessoal e social, sua validade para a análise e compreensão de fatos da vida real.

A maioria $(87,4 \%)$ dos alunos acredita que a licenciatura não os prepara para a reconstrução do saber científico em saber escolar (afirmativa 12). No entanto, entre os entrevistados que já se formaram não há um consenso quanto a esta questão. Mas, nessa categoria, a maioria daqueles que discordam não leciona $(62,5 \%)$. Já a maior parte dos que estão dando aula concordam que a licenciatura não dá instrumentos suficientes para que o professor possa fazer essa mediação (45,3\%). É interessante perceber também que este último grupo tem uma avaliação mais crítica em relação a sua preparação para lecionar aulas teóricas. Dentre eles, apenas $40 \%$ acreditam que o curso forma professores bem preparados para ministrar aulas teóricas (afirmativa 1), enquanto que no grupo de formados que não lecionam, este número sobe para $75 \%$. Essa visão mais crítica dos professores em relação àqueles que tiveram apenas uma 
pequena experiência com a docência pode ser observada, mais uma vez, quando apenas 9\% dos professores entrevistados se diz capaz de aplicar teorias pedagógicas na dinâmica de sala de aula, enquanto entre os ex-alunos que não lecionam esse percentual é de $62,5 \%$ (afirmativa 15 ).

Entre os entrevistados 54,2\% concordam que as disciplinas da Faculdade de Educação (FaE) do curso de licenciatura em Ciências Biológicas enfocam apenas as teorias pedagógicas (afirmativa 8). De acordo com CANDAU \& LELIS (1999), essa abordagem dissociativa tende a enfatizar a formação teórica sem se preocupar em modificar ou fornecer instrumentos para a intervenção na prática educacional. Essa afirmativa pode ser confirmada pela dificuldade apontada por $40 \%$ dos entrevistados em aplicar as teorias pedagógicas na dinâmica da sala de aula (afirmativa 15).

A disciplina Didática de Licenciatura propõe uma análise das fundamentações de diferentes propostas de ensino-aprendizagem e dos elementos deste processo, incluindo a relação teoria e prática pedagógica; reflexão da sala de aula como espaço de mediação sócio-cultural, produção e apropriação do conhecimento; e elaboração de uma proposta alternativa de ensino. Mesmo sendo objetivo da disciplina trabalhar o planejamento e a preparação de aulas, os dados da afirmativa 6 mostram que a maioria dos entrevistados acredita que ela não cumpre com esse propósito (71,3\%). Além disso, o programa infere que esta seria uma das disciplinas que nortearia a prática pedagógica, mas pela análise da questão 24 , percebemos que a abordagem da relação teoria/prática no curso ainda é insuficiente $(71,3 \%)$.

O programa da Prática de Ensino mostra que esta é a disciplina responsável por uma maior abordagem da relação entre teoria e prática docente. Porém, entre os alunos não há um consenso de que esta é a única disciplina que permite relacionar as teorias pedagógicas com a atividade do professor em sala de aula (apenas 37,5\% concordam com a afirmativa 10). Contudo, percebe-se a importância desta disciplina para essa integração, uma vez que $62,4 \%$ deles acreditam que entenderiam melhor a aplicação das disciplinas da licenciatura na prática docente se as atividades da Prática de Ensino ocorressem desde o começo do curso de licenciatura (afirmativa 15).

No grupo de entrevistados que já estão formados (incluindo os que lecionam) não há dados significativos sobre o enfoque centrado em teorias pedagógicas pelas disciplinas da $\mathrm{FaE}$ (36,8\% concordam e 31,5\% discordam com a afirmativa 8). Porém, 57,9\% deles acreditam que a Prática de Ensino é a única disciplina que relaciona teorias pedagógicas com a atividade do professor (afirmativa 10). Ou seja, mesmo que 
as demais disciplinas da $\mathrm{FaE}$ abordem outros aspectos que não as teorias pedagógicas, a relação entre estas e a prática docente para esses ex-alunos é trabalhada predominantemente na Prática de Ensino.

Percebe-se assim que esta é uma disciplina chave na mediação das teorias pedagógicas para a atividade docente. Portanto, levantamos a hipótese de que a porcentagem significativa de alunos indecisos $(31,2 \%)$ e daqueles que não são capazes de realizar esta mediação (50\%) (afirmativa 15), deve-se ao fato de que em nenhum ou em poucos momentos do curso tiveram a oportunidade de trabalhar este aspecto, pois estavam iniciando as atividades da disciplina no momento da coleta dos dados. Dentre o grupo que já passou pela Prática de Ensino, os que não lecionam sentem-se mais bem preparados para a mediação, ao contrário daqueles que estão lecionando que, com a experiência de sala de aula, acreditam que esta preparação não foi suficiente. MELLO (2000) defende que desde o primeiro ano e em todas as disciplinas de uma licenciatura especializada o exercício de mediação didática do conteúdo e a prática de ensino deveriam estar lado a lado.

Através de uma análise mais abrangente do questionário, envolvendo as questões $13,15,18$, e 24 , pode-se perceber que há uma demanda em se trabalhar mais a fundo a relação teoria-prática educacional de uma forma associada, para que o professor possa entender e participar melhor da dinâmica em sala de aula. Esses dados mostram que a relação teoria e prática na estrutura do curso é trabalhada de forma dicotômica e, provavelmente por isso, $74,2 \%$ dos entrevistados não concordam com essa atual estrutura, onde há uma clara divisão entre disciplinas teóricas e instrumentais (afirmativa 13) .

\section{- Questionário submetido aos professores do curso de Licenciatura}

As atividades propostas pelos professores entrevistados em suas disciplinas estão de acordo com as ementas das mesmas. Desta forma, as disciplinas instrumentais trabalham predominantemente atividades práticas e a teoria é abordada de forma pontual e isolada. Em apenas uma dessas disciplinas ficou claro que a teoria e a prática são trabalhadas juntas. Já as disciplinas da Faculdade de Educação se encarregam de abordar as teorias pedagógicas e a relação do trabalho do professor com as mesmas. Mas, com os dados obtidos pelos questionários submetidos aos 
alunos e ex-alunos, percebe-se que esta abordagem não é suficiente para preparar o professor nesse aspecto.

Todos os professores entrevistados acreditam que o conteúdo das disciplinas específicas do ciclo básico (bioquímica, ecologia, zoologia, fisiologia...) é aplicável ao trabalho do professor, uma vez que a formação científica ampla e profunda do curso proporciona a base conceitual necessária para a prática pedagógica. Porém, só cinco dos entrevistados explicitam a necessidade de se trabalhar a mediação didática para uma boa atuação pedagógica. Dentre estes, um afirma que há uma carência dessa abordagem no curso de licenciatura, dois acreditam que a mediação é trabalhada nas disciplinas instrumentais e dois não deixam claro quais disciplinas têm esse papel.

Dois professores responsabilizam as disciplinas do Instituto de Ciências Biológicas (ICB) pela formação científica e as disciplinas da Faculdade de Educação (FaE) pela formação pedagógica, enquanto outros dois queixam-se desse distanciamento entre as instituições. Os outros quatro não definiram uma opinião.

Assim, pode-se constatar que há uma clara divisão de tarefas dentro do currículo do curso, havendo pouco diálogo entre a $\mathrm{FaE}$ e o ICB, o que implica na dicotomia entre teoria e prática na formação do professor. Poucas matérias se propõem a fazer a relação entre esses dois pólos. Além disso, percebe-se a dificuldade em trabalhar esse aspecto, como relatado por um dos professores entrevistados:

Estabelecer uma relação entre este quadro teórico e a prática docente tem sido um grande desafio... Muitas vezes tenho a sensação de que há pouco interesse por parte dos alunos por este conhecimento. Além disso, seu significado se perde em meio às "urgências" e demandas da realidade escolar. Assim, a interlocução entre este saber acadêmico e o trabalho do professor fica limitada.

\section{CONCLUSÃO}

No referencial teórico em que nos baseamos encontramos fundamentações para nossas queixas a respeito da separação, ou mesmo oposição, entre teoria e prática. Apesar do desejo de buscar novas formas de relacionamento entre estas duas dimensões da realidade, o que se observa na maioria dos cursos de preparação de docentes é que se prioriza a visão dissociativa. De acordo com a literatura, essas 
tendências podem ser explicadas pela dificuldade em transformar o saber de referência em saber escolar, fenômeno entendido neste trabalho como mediação didática.

Com este trabalho foi possível entender um pouco mais sobre a relação teoriaprática no curso de Licenciatura em Ciências Biológicas da UFMG. Percebemos que há uma grande separação na abordagem desses dois pólos, tornando o currículo fragmentado. Constatamos também que não há diálogo entre o Instituto de Ciências Biológicas e a Faculdade de Educação, o que torna óbvia a existência desta dicotomia.

Através dos dados obtidos pelos questionários e com ajuda da literatura especializada percebemos mais claramente estas questões. No entanto, não foi uma tarefa fácil a construção dos questionários. Transformar os tópicos em que nos baseamos em questões contextualizadas, objetivas e claras para os entrevistados foi, certamente, a etapa mais complicada.

Ao analisarmos os dados obtidos, acreditamos que algumas modificações ainda poderiam ser feitas a fim de obtermos resultados mais precisos. Contradições detectadas nas respostas de alguns entrevistados nos levaram a pensar que algumas expressões, tais como, "fundamentação de atividade prática em um conteúdo teórico", "reconstrução do saber científico", "relação de atividade prática ao conteúdo teórico correspondente", podem não ter sido interpretadas da mesma forma como foram utilizadas no contexto deste trabalho.

Para nós foi muito complicado analisar os dados e fazer relações entre eles, considerando a individualidade de cada entrevistado e possíveis variáveis externas que os possam ter influenciado. Contudo, a experiência de pesquisa em educação foi enriquecedora, nos possibilitando conhecer novas metodologias, onde as análises devem ser mais flexíveis, para a incorporação de todas essas variáveis.

Esperamos que este episódio de iniciação à pesquisa possa chamar atenção para as considerações nela levantadas, as quais nos parecem de grande relevância para a formação do educador. Através do diálogo entre os professores e da reformulação das ementas ou criação de disciplinas, seria possível minimizar a distância que existe entre a abordagem teórica e a prática no curso de Licenciatura em Ciências Biológicas da UFMG.

No entanto, também é preciso uma maior reflexão e olhar crítico dos alunos em relação à formação do educador para que mudanças concretas ocorram. Esperamos que este nosso trabalho incentive outras pesquisas e reflexões, onde os alunos 
A relação teoria-prática na formação do educador

questionem a formação acadêmica do professor, ajudando a construir um currículo mais coerente com a realidade da sala de aula na educação básica.

Para finalizar, utilizamos a fala de LELIS (2001), que sintetiza o que buscamos neste trabalho:

Se estas questões podem contribuir como bússolas em nossas pesquisas, certamente será a experiência prática e concreta, com a ajuda das lições do passado, que nos ajudará a buscar novos objetos, novos problemas, novos idiomas pedagógicos.

\section{ANEXO 1 - Questionário submetido aos alunos e ex-alunos do curso de Licenciatura em Ciências Biológicas/UFMG}

Sexo: Idade: Está lecionando?

Há quanto tempo? Nível de atuação: ? Fundamental ? Médio

Ano em que se formou:

Tempo de docência: Nível de atuação: Fundamental Médio

Marque um $\mathbf{x}$ no item que mais se aproxima da sua opinião sobre as afirmativas abaixo:

1- concorda fortemente, 2- concorda, 3- indeciso, 4- discorda, 5- discorda fortemente

\begin{tabular}{|l|l|l|l|l|l|}
\hline Questões & $\mathbf{1}$ & $\mathbf{2}$ & $\mathbf{3}$ & $\mathbf{4}$ & $\mathbf{5}$ \\
\hline $\begin{array}{l}\text { 1. Acredito que o curso de licenciatura forma professores bem } \\
\text { preparados para ministrar aulas teóricas para a educação básica. }\end{array}$ & & & & \\
\hline $\begin{array}{l}\text { 2. Acredito que nas disciplinas instrumentais ' um predomínio de } \\
\text { atividades práticas. }\end{array}$ & & & & \\
\hline $\begin{array}{l}\text { 3. A linguagem científica é acessível aos alunos de ensino } \\
\text { médio/fundamental. }\end{array}$ & & & & \\
\hline $\begin{array}{l}\text { 4. Depois de cursar as disciplinas da licenciatura, o futuro professor está } \\
\text { muito bem preparado para propor atividades práticas para alunos de } \\
\text { educação básica. }\end{array}$ & & & & \\
\hline $\begin{array}{l}\text { 5. As atividades das disciplinas instrumentais incluem a preparação de } \\
\text { aulas teóricas para a educação básica. }\end{array}$ & & & & \\
\hline
\end{tabular}

1 Instrumentação do Ensino de Ecologia, Zoologia, Botânica... 
6. Acredito que na disciplina Didática de Licenciatura aprendi como se preparam boas aulas.

7. Ao preparar uma atividade prática para alunos da educação básica sinto dificuldades de fundamenta-la em um conteúdo teórico.

8. As disciplinas da Faculdade de Educação do curso de licenciatura enfocam apenas as teorias pedagógicas.

9. E papel das disciplinas instrumentais tratar da abordagem teórica adequada para alunos da educação básica.

10. Acredito que a Prática de Ensino é a única disciplina da Licenciatura que permite relacionar as teorias pedagógicas com a atividade do professor em sala de aula.

11. Acredito que o saber científico deve ser reconstruído para ser utilizado no contexto escolar.

12. A licenciatura prepara os futuros professores para a reconstrução do saber científico no contexto escolar.

13. Concordo com a estrutura atual do currículo de licenciatura onde há uma clara divisão entre disciplinas teóricas e instrumentais.

14. Acredito que as atividades práticas das disciplinas instrumentais são relacionadas aos conteúdos teóricos correspondentes.

15. Acredito ser capaz de aplicar as teorias pedagógicas estudadas no curso de licenciatura para entender e participar melhor da dinâmica de sala de aula da educação básica.

16. Ao preparar uma aula teórica para alunos da educação básica, sinto dificuldades de extrapolar o conteúdo para uma atividade (ou exemplo) prática(o).

17. Linguagem escolar e linguagem científica são a mesma coisa.

18. Acredito que entenderia melhor a aplicação das disciplinas da Licenciatura na prática docente se as atividades da Prática de Ensino ocorressem desde o começo do curso de Licenciatura.

19. Acredito que ser professor é mais do que saber preparar boas aulas práticas.

20. Acredito que um bom professor deve saber preparar boas aulas teóricas.

21. Ser professor é saber transformar um conteúdo teórico em algo que os alunos entendam.

22. Sou indiferente a qualquer mudança no currículo de Licenciatura, porque o importante mesmo para ser professor é ter o dom de ensinar.

23. Sou indiferente a qualquer mudança no currículo de Licenciatura, porque o importante mesmo para ser professor é dominar o conteúdo.

24. Acredito que o curso de licenciatura oferece poucas disciplinas que ajudam a relacionar o conteúdo de biologia com o conteúdo pedagógico. 


\section{ANEXO 2 - Questionário submetido aos professores universitários do curso de licenciatura em Ciências Biológicas/UFMG}

Sexo:

Idade: Tempo de Docência:

Disciplina Ministrada na Licenciatura:

A teoria, a que nos referimos neste questionário, está relacionada aos conteúdos específicos de biologia (bioquímica, ecologia, zoologia, fisiologia...).

1. Quais atividades você propõe aos alunos em sua disciplina?

2. O seu curso possui alguma abordagem teórica? Em caso de resposta afirmativa explicite como ela é feita.

3. Você acredita que o conteúdo teórico visto pelos alunos nas disciplinas do ciclo básico (bioquímica, ecologia, zoologia, fisiologia...) é aplicável ao trabalho do professor de biologia do ensino fundamental/médio? Aponte suas razões.

4. Na sua opinião, as disciplinas específicas da licenciatura contribuem para o embasamento teórico necessário para a atuação pedagógica dos futuros professores do ensino fundamental/médio? Aponte suas razões. 


\section{ANEXO 3 - Respostas aos questionários submetidos aos alunos e ex-alunos do curso de licenciatura em Ciências Biológicas/UFMG}

Tabela1 - Respostas de todos os entrevistados

\begin{tabular}{cccccc}
\hline \multirow{2}{*}{ Afirmativas } & \multicolumn{5}{c}{ Pontuação na escala de pontos $(\%)$} \\
\cline { 2 - 6 } & 1 & 2 & 3 & 4 & 5 \\
\hline 1 & 2,9 & 35,2 & 14,7 & 35,2 & 5,8 \\
2 & 14,2 & 57,1 & 11,4 & 17,1 & 0 \\
3 & 2,8 & 2,8 & 25,7 & 45,7 & 22,8 \\
4 & 2,8 & 14,2 & 22,8 & 42,8 & 17,1 \\
5 & 5,7 & 60 & 14,2 & 17,1 & 2,8 \\
6 & 0 & 14,2 & 14,2 & 37,1 & 34,2 \\
7 & 2,8 & 14,2 & 17,1 & 40 & 25,7 \\
8 & 5,7 & 48,5 & 22,8 & 20 & 2,8 \\
9 & 5,7 & 57,1 & 17,1 & 11,4 & 8,5 \\
10 & 25,7 & 22,8 & 22,8 & 25,7 & 2,8 \\
11 & 22,8 & 54,2 & 14,2 & 5,7 & 2,8 \\
12 & 2,8 & 20 & 17,1 & 42,8 & 17,1 \\
13 & 0 & 8,5 & 17,1 & 40 & 34,2 \\
14 & 8,5 & 65,7 & 5,7 & 20 & 0 \\
15 & 2,8 & 25,7 & 31,4 & 20 & 20 \\
16 & 2,8 & 31,4 & 31,4 & 28,5 & 2,8 \\
17 & 2,8 & 0 & 2,8 & 54,2 & 40 \\
18 & 40 & 34,2 & 11,4 & 11,4 & 2,8 \\
19 & 71,4 & 28,5 & 0 & 0 & 0 \\
20 & 40 & 54,2 & 5,7 & 0 & 0 \\
21 & 51,4 & 40 & 5,7 & 2,8 & 0 \\
22 & 0 & 0 & 2,9 & 29,4 & 67,6 \\
23 & 0 & 0 & 2,8 & 34,2 & 62,8 \\
24 & 28,5 & 42,8 & 14,2 & 11,4 & 2,8 \\
\hline
\end{tabular}

Tabela 2 - Resposta dos alunos do curso de licenciatura em Ciências

\begin{tabular}{cccccc}
\multicolumn{6}{c}{ Biológicas/UFMG } \\
\hline \multirow{2}{*}{ Afirmativas } & \multicolumn{5}{c}{ Pontuação na escala de pontos $(\%)$} \\
\cline { 2 - 6 } & 1 & 2 & 3 & 4 & 5 \\
\hline 1 & 0 & 33,3 & 20 & 33,3 & 13,3 \\
2 & 6,2 & 62,5 & 6,2 & 25 & 0 \\
3 & 6,2 & 0 & 25 & 50 & 18,7 \\
4 & 0 & 12,5 & 18,7 & 43,7 & 25 \\
5 & 0 & 62,5 & 25 & 12,5 & 0 \\
6 & 0 & 18,7 & 18,7 & 31,2 & 31,2 \\
7 & 6,2 & 25 & 6,2 & 37,5 & 25 \\
8 & 6,2 & 68,7 & 12,5 & 12,5 & 0 \\
9 & 0 & 81,2 & 12,5 & 0 & 6,2 \\
10 & 0 & 37,5 & 31,2 & 31,2 & 0 \\
11 & 12,5 & 50 & 25 & 12,5 & 0 \\
12 & 0 & 0 & 12,5 & 68,7 & 18,7 \\
13 & 0 & 6,2 & 6,2 & 50 & 37,5 \\
14 & 6,2 & 62,5 & 6,2 & 25 & 0 \\
15 & 0 & 18,7 & 31,2 & 25 & 25 \\
16 & 6,2 & 31,2 & 37,5 & 18,7 & 6,2 \\
17 & 6,2 & 0 & 6,2 & 56,2 & 31,2 \\
18 & 18,7 & 43,7 & 25 & 12,5 & 0 \\
19 & 62,5 & 37,5 & 0 & 0 & 0 \\
20 & 37,5 & 56,2 & 6,2 & 0 & 0 \\
21 & 43,7 & 43,7 & 6,2 & 6,2 & 0 \\
22 & 0 & 0 & 6,6 & 40 & 53,3 \\
23 & 0 & 0 & 6,2 & 37,5 & 56,2 \\
24 & 25 & 43,7 & 12,5 & 18,7 & 0 \\
\hline
\end{tabular}

Legenda da escala de pontos: 1 - Concordo fortemente; 2 - concordo; 3 - indeciso; 4 - discordo; 5 - discordo fortemente 
Tabela 3 - Respostas dos ex-alunos do curso de licenciatura em

Ciências Biológicas/UFMG

\begin{tabular}{cccccc}
\hline \multirow{2}{*}{ Afirmativas } & \multicolumn{5}{c}{ Pontuação na escala de pontos (\%) } \\
\cline { 2 - 6 } & 1 & 2 & 3 & 4 & 5 \\
\hline 1 & 0 & 75 & 0 & 25 & 0 \\
2 & 12,5 & 75 & 0 & 12,5 & 0 \\
3 & 0 & 12,5 & 37,5 & 37,5 & 12,5 \\
4 & 12,5 & 12,5 & 25 & 37,5 & 12,5 \\
5 & 12,5 & 62,5 & 0 & 25 & 0 \\
6 & 0 & 12,5 & 12,5 & 62,5 & 12,5 \\
7 & 0 & 0 & 37,5 & 25 & 37,5 \\
8 & 0 & 12,5 & 37,5 & 37,5 & 12,5 \\
9 & 12,5 & 37,5 & 12,5 & 25 & 12,5 \\
10 & 37,5 & 12,5 & 12,5 & 25 & 12,5 \\
11 & 37,5 & 50 & 0 & 0 & 12,5 \\
12 & 0 & 62,5 & 12,5 & 25 & 0 \\
13 & 0 & 12,5 & 37,5 & 25 & 25 \\
14 & 0 & 100 & 0 & 0 & 0 \\
15 & 0 & 62,5 & 12,5 & 0 & 25 \\
16 & 0 & 37,5 & 37,5 & 25 & 0 \\
17 & 0 & 0 & 0 & 50 & 50 \\
18 & 50 & 37,5 & 0 & 12,5 & 0 \\
19 & 62,5 & 37,5 & 0 & 0 & 0 \\
20 & 25 & 75 & 0 & 0 & 0 \\
21 & 50 & 50 & 0 & 0 & 0 \\
22 & 0 & 0 & 0 & 25 & 75 \\
23 & 0 & 0 & 0 & 12,5 & 87,5 \\
24 & 37,5 & 37,5 & 0 & 12,5 & 12,5 \\
\hline
\end{tabular}

Tabela 4 - Respostas dos professores de Ciências formados na UFMG

\begin{tabular}{cccccc}
\hline \multirow{2}{*}{ Afirmativas } & \multicolumn{5}{c}{ Pontuação na escala de pontos (\%) } \\
\cline { 2 - 6 } & 1 & 2 & 3 & 4 & 5 \\
\hline 1 & 9 & 27,2 & 18,1 & 45,4 & 0 \\
2 & 27,2 & 36,3 & 27,2 & 9 & 0 \\
3 & 0 & 0 & 18,1 & 45,4 & 36,3 \\
4 & 0 & 18,1 & 27,2 & 45,4 & 9 \\
5 & 0 & 54,5 & 9 & 18,1 & 9 \\
6 & 0 & 9 & 9 & 27,2 & 54,5 \\
7 & 0 & 9 & 18,1 & 54,5 & 18,1 \\
8 & 9 & 45,4 & 27,7 & 18,1 & 0 \\
9 & 9 & 36,3 & 27,2 & 18,1 & 9 \\
10 & 54,5 & 9 & 18,1 & 18,1 & 0 \\
11 & 27,7 & 63,6 & 9 & 0 & 0 \\
12 & 9 & 18,1 & 27,2 & 18,1 & 27,2 \\
13 & 0 & 9 & 18,1 & 36,3 & 36,3 \\
14 & 18,1 & 45,4 & 9 & 27,2 & 0 \\
15 & 9 & 9 & 45,4 & 27,2 & 9 \\
16 & 0 & 27,2 & 18,1 & 45,4 & 9 \\
17 & 0 & 0 & 0 & 54,5 & 45,4 \\
18 & 63,6 & 18,1 & 0 & 9 & 9 \\
19 & 90,9 & 9 & 0 & 0 & 0 \\
20 & 54,4 & 36,3 & 9 & 0 & 0 \\
21 & 63,6 & 27,2 & 9 & 0 & 0 \\
22 & 0 & 0 & 0 & 18,1 & 81,8 \\
23 & 0 & 0 & 0 & 45,4 & 54,5 \\
24 & 27,2 & 45,4 & 27,2 & 0 & 0 \\
\hline
\end{tabular}

Legenda da escala de pontos: 1 - Concordo fortemente; 2 - concordo; 3 - indeciso; 4 - discordo; 5 - discordo fortemente 
A relação teoria-prática na formação do educador

\section{AGRADECIMENTOS}

Agradecemos imensamente à professora Regina Mendes pela participação ativa na elaboração, realização e estruturação desse trabalho, pelo estímulo e pelas intermináveis horas de dedicação. Ao Ely Maués pela contribuição valiosa na concepção e construção da metodologia. A todos os professores, alunos e ex-alunos, pela disponibilidade e por tornarem possível essa pesquisa.

\section{REFERÊNCIAS BIBLIOGRÁFICAS}

CANDAU, V.M.F. Universidade e formação de professores: Que rumos tomar? In: CANDAU, V.M.F. (org.) Magistério, construção cotidiana. Petrópolis: Vozes, 1997 apud LELIS, I.A. Do Ensino de Conteúdos aos Saberes do Professor: Mudança de Idioma Pedagógico? Educação \& Sociedade, ano XXII, no 74, abril 2001. Campinas, SP: Cedes.

CANDAU, V.M. \& LELIS, I.A. A Relação Teoria-Prática na Formação do educador. In: CANDAU, V.M (Org.). Rumo a uma Nova Didática. 10 ed. Petrópolis: Vozes. 1999. p.56-72.

CHEVALLARD, Yves. La transposition didactique: du savoir savant au savoir enseigné. Grenoble: La Pensée Sauvage. 1985.

DEVELAY, MICHEL. De l'apprentissage à l'enseignment - pour une épistémologie scolaire. Paris: ESF, $1995^{\mathrm{a}}$ apud LOPES, A.R.C. Organização do conhecimento escolar: analisando a disciplinaridade e a integração. In: CANDAU, V.M (Org.). Linguagens, Espaços e Tempos no Ensinar e Aprender (X ENDIPE). RJ: DP\&A, 2000 (147-163).

DEVELAY, MICHEL.(org.). Savoirs scolaires et didactiques des disciplines - une encyclopédie pour aujourd'hui. Paris: ESF, 1995b apud LOPES, A.R.C. Organização do conhecimento escolar: analisando a disciplinaridade e a integração. In: CANDAU, V.M (Org.). Linguagens, Espaços e Tempos no Ensinar e Aprender (X ENDIPE). RJ: DP\&A, 2000 (147-163). 
FIORENTINI, D. \& SOUZA e MELO,G.F. Saberes docentes: Um desafio para acadêmicos e práticos. In: GERALDI, C. (org.) Cartografias do trabalho docente: Professor(a)-pesquisador(a). Campinas: Mercado das Letras, ALB, 1998, p. 307-335 apud LELIS, I.A. Do Ensino de Conteúdos aos Saberes do Professor: Mudança de Idioma Pedagógico? Educação \& Sociedade, ano XXII, $\mathrm{n}^{\mathrm{o}} 74$, abril 2001. Campinas, SP: Cedes.

LELIS, I.A. Do Ensino de Conteúdos aos Saberes do Professor: Mudança de Idioma Pedagógico? Educação \& Sociedade, ano XXII, n 74, abril 2001. Campinas, SP: Cedes.

LOPES, A.R.C. Conhecimento Escolar: Processos de Seleção Cultural e de Mediação Didática. Educação e Realidade. 22 (1): 95/12 Jan./Jun. 1997.

LOPES, A.R.C. Organização do conhecimento escolar: analisando a disciplinaridade e a integração. In: CANDAU, V.M (Org.). Linguagens, Espaços e Tempos no Ensinar e Aprender (X ENDIPE). RJ: DP\&A, 2000 (147163).

MELLO, G. N. Formação inicial de professores para a educação básica uma (re)visão radical. São Paulo em Perspectiva, n. 1,vol. 14,. São Paulo: SEADE, 2000, p. $98-110$

MORTIMER, E. F. Sobre Chamas e Cristais: A Linguagem Científica, A Linguagem Cotidiana e O Ensino de Ciências. In: Ciência, ética e cultura na educação. 1 ed. SÃO LEOPOLDO, 1998, v. , p. 099-118.

PEREIRA, J. E. D. Formação de Professores - pesquisa, representações e poder. Belo Horizonte: Autêntica, 2000.

SANTOS, L. L. C. P. Formação de professores e qualidade de ensino. In: Escola Básica. Campinas, Papirus, 1992, p. 137-146. 
SAVIANI, D.A. Pedagogia histórico-crítica no quadro das tendências da Educação Brasileira. ANDE - Revista da Associação Nacional de Educação nº11, São Paulo: Cortez, 1985, p.15-23 apud LELIS, I.A. Do Ensino de Conteúdos aos Saberes do Professor: Mudança de Idioma Pedagógico? Educação \& Sociedade, ano XXII, n ${ }^{0} 74$, abril 2001. Campinas, SP: Cedes.

SAVIANI, D.A. Educação: do Censo Comum à Consciência Filosófica. 12 ed. Campinas, SP: Autores Associados, 1996.

SCHON, D.A. The Reflective Practitioner. Basic Books, New York, 1982 apud SANTOS, L. L. C. P. Formação de professores e qualidade de ensino. In: Escola Básica. Campinas, Papirus, 1992, p. 137-146.

VASQUEZ, A.S. Filosofia da práxis. Rio de Janeiro, Paz e Terra, 1977 apud CANDAU, V.M. e LELIS, I.A. A Relação Teoria-Prática na Formação do educador. In: CANDAU, V.M (Org.). Rumo a uma Nova Didática. 10 ed. Petrópolis: Vozes. 1999. p.56-72. 